\title{
Canine Model For The Study of the Epigenetic Factors Involved in Mammary Tumor Development
}

\author{
Adriana Amfim 1(D), Anca Botezatu ${ }^{2}{ }^{(\mathbb{D})}$, Gabriela Anton ${ }^{2}{ }^{(\mathbb{D})}$, Liliana Burlibasa ${ }^{3}{ }^{(\mathbb{D})}$, Otilia Zarnescu ${ }^{3(\mathbb{D})}$, \\ Camelia Albu $^{4}$, Marioara Matei $5,8^{(D)}$, Andrei Tanase 6(D), Lucian Gabriel Radu 4 (D), Lygia \\ Alexandrescu ${ }^{7(D)}$, Natalia Cucu ${ }^{3,8}$ (D)

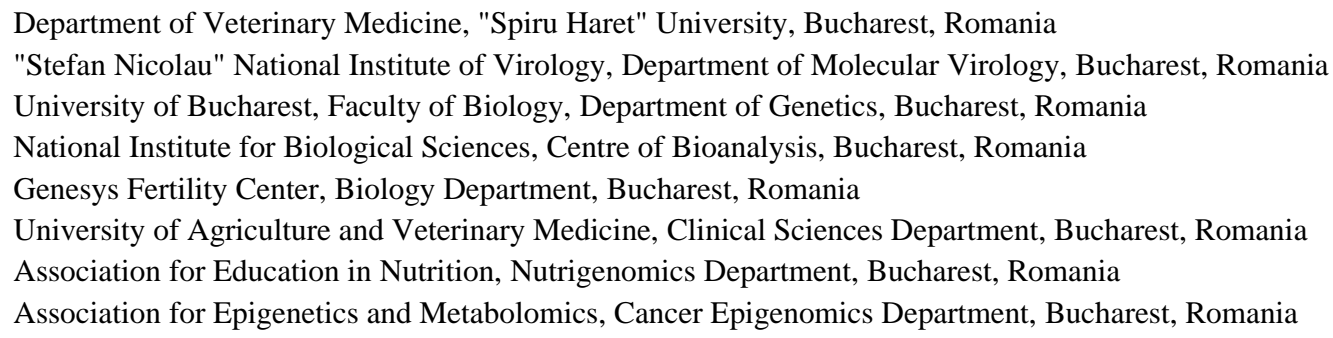

Received: 25.05.2020; Revised: 14.06.2020; Accepted: 15.06.2020; Published: 17.06.2020

\begin{abstract}
Cancer is a multifactorial disease involving reprogramming of the gene function in normal cells through both genetic and epigenetic factors. The latter ones are essentially represented by chromatin remodeling factors as transcriptional control of gene expression at the nucleus level. Certain sets of tumor suppression genes controlling vital cell functions such as cell cycle, DNA repair, cell adhesion, and apoptosis are considered candidate genes for defining specific types of cancer. Their silencing may be achieved through somatic mutations or by epigenetic factors as DNA methylation and histone covalent modification. Two major DNA methylation patterns have been described in mammary gland tumors: genome hypomethylation and concomitant "in situ" hypermethylation in critical genes. Human mammary gland cancer has been studied through animal models, canine one offering opportunity to investigate the molecular aspects that better define the borderline between the primary inflammatory and tumor progression processes. In contrast, both humans and dogs share the same challenging environment. This work presents the preliminary results in a study of the transcriptional epigenetic markers identified in canine mammary glands during tumor development. Bisulfite mutagenesis based methylation-specific (MS)- PCR has been performed for the estimation of BRCAl, and $B R C A 2$ gene promoter hyper-methylation profiles, concomitant to methylation sensible restriction of genomic DNA in order to estimate the global hypo-methylation status have been performed on 9 DNA samples obtained from clinically selected canine tumor tissues. Histone H3K9 trimethylated was stained by immunohistochemical methods (IHC) in normal and tumor tissues. The results are discussed through their crosstalk with DNA methylation dynamics in order to highlight the cancer initiation and progression processes in the context of heritability and the causes of sporadic cases.
\end{abstract}

Keywords: canine mammary tumor; breast cancer; DNA methylation; BRCA 1, 2; estrogen receptor alpha, epigenetic; model.

(C) 2020 by the authors. This article is an open-access article distributed under the terms and conditions of the Creative Commons Attribution (CC BY) license (https://creativecommons.org/licenses/by/4.0/).

\section{Introduction}

According to Shimizu R. and colab., (2016), breast cancer is considered the most prevalent neoplasm in women [1]. While the diagnostic methods are more precise in humans, 
it is still difficult to estimate the real incidence or prevalence of the same tumors in animals in general and in Romania in particular. The explanation points to the fact that while in human medicine, cancer cases have been reported since 1940, in veterinary medicine, cancer cases have been collected in a non-organized method. According to the epidemiological studies, human breast cancer is a leading cause of death, accounting for 8.8 million deaths in 2015 [1,2]. In veterinary medicine, mammary gland tumors are frequent in dogs and cats. In lady dogs, the incidence of mammary tumors is estimated at $50 \%$ of all neoplasms (approximately $60 \%$ are benign, and $40 \%$ malignant). The mean onset age for canine mammary tumors is between 10 and 11 years, and higher incidence has been reported for only some breeds such as Poodle, English Spaniel, Brittany Spaniel, Boston Terrier, while for other, Chihuahua and Boxer breeds, the lower incidence has been observed [3]. In our country, recent studies have shown that $88.09 \%$ of tumor cases were recorded in dogs and $11.91 \%$ in cats; $61.54 \%$ of tumors were recorded in female dogs and $38.45 \%$ in male dogs; the most prevalent types of tumors affecting female dogs were carcinoma (47\%); the most common type of tumor encountered in male dogs was the mast cell tumor (11.5\%). The mammary gland and skin are mostly affected by neoplasms in female dogs. In contrast, in male dogs, the most prevalent systems affected by tumors involved the skin and the reproductive system [4]. Moreover, as research has highlighted that canine and feline mammary tumors present relative age of onset and similar human-environmental risk factors, their biological behavior, metastases pattern as well as molecular and genetic features are more and more recognized as proper natural models for human breast cancer studies [5].

Over time, animal models for examining human breast cancer (HBC) in terms of molecular mechanisms of tumor initiation and development processes have been extensively studied and proposed. The most frequently used experimental models, especially for preclinical research in tumors, are "in vitro" models based on tissue-derived cell lines. However, they are limited to experimental conditions, which make them poorly representative of real cancers; they have been replaced by "in vivo" models, including xenografts, as well as syngenetic and genetically engineered mice, and also some domestic animals (cats and dogs) [6]. Although rodents were the most frequently used animal models in cancer research, a notable difference has been observed in the tumor pathogeny and biology between rodents and humans, which limited this animal model to be used in human cancer research: (i) "in vitro", and potentially "in vivo" rodent cell genetic and epigenetic transformation involve fewer regulatory factors [7]; (ii) human and mouse cells exhibit considerable differences in telomerase regulation and telomere dynamics [8] and (iii) rodents are intrinsically more susceptible than humans to carcinogenesis, therefore in wild-type rodents, sporadic cancers are relatively rare [9].

With the recent advent of molecular diagnosis, significant attention has been focused on the dog as a model for human cancer. Scientific reasoning could support several theories regarding the use of a canine model in human breast cancer research. First, investigating molecular mechanisms of the multistep tumor development processes in humans, especially in solid mammary tumors, is frequently impractical and, in most cases, unethical. Therefore, relevant animal models study provide interesting opportunities for deciphering the initiation and progression steps of the tumor development process. Another aspect would be related to the sporadic development of mammary tumors and other cancer types in dogs with supposed intact immune systems, which exhibit a number of clinical and molecular similarities to HBC. In female dogs, mammary gland tumors are also among the most frequent tumors, and the epidemiological and histo-pathological similarities between spontaneous tumors of dogs and 
their human counterparts make them suitable natural models for human cancer research [5]. In addition to the spontaneous tumor presentation, the clinical similarities between human and canine mammary tumors (CMT) include age, hormonal etiology, and course of the diseases. Several hormonal common factors are involved in mammary carcinogenesis, and the status of estrogen is one of them $[9,10]$. On the other hand, dogs are the one domestic animal that shares the human environment. Therefore, determining environmental risk factors for canine tumors may contribute to the identification and understanding of such risk factors for similar tumors in humans. From the multifactorial, environmental perspective, dogs hold a unique status in human BC studies with respect to epigenetic aberrations since especially companion dogs and their owners share neighborhood environments and might be exposed to the same nutritional factors and carcinogens [2]. For this reason, epigenetic factors are considered as key modulators of gene expression. Together with genetic factors and cell biology of tumor development, they are considered presently as very useful for comparison between human and canine oncology studies [11]. These biomarkers can inform about the stage of a disease, results of onco-treatment, or prognosis for the patient. Every cancer cell expresses specific proteins that are called tumor-associated antigens [12]. These aspects were observed in association with several human cancer predisposition genes, which have also been discovered in the constitutional (germline) DNA of dogs with cancer, including mutations in BRCA1, BRCA2, and p53 coding genes [13, 14]. Since it was identified and cloned in 1994, BRCA1 became a major cancer predisposition gene, with a tumor-suppressive role proved both in humans and dogs [15]. The canine $B R C A 2$ is a tumor suppressor gene, too, encoding a protein involved in DNA repair through its interaction with RAD51 recombinase [16]. The hormone estrogen is considered one of the most important causes of tumors, and its main role in tumor initiation and progression is linked with its binding ability to its receptor: estrogen receptor $\alpha(E R \alpha)$ and its interaction with the progesterone receptor (PR) [17]. For this reason ER $\alpha$ has become a prognostic biomarker and therapeutic target in HBC [18] and also in the canine mammary tumor: the majority of canine mammary tumors (CMT) (benign and malignant) express ER and/or PR [19]. Given the high homology between the canine genome sequence and its human counterpart, a number of molecular markers associated with tumor development have been identified. Of the numerous genes identified as being responsible for breast cancer initiation and development in humans, a set of them were also demonstrated to serve essential roles in canine tumor development too [20].

Epigenetic mechanisms can presently complete and bring more information in cancer pathogeny, especially focusing on sporadic cases, when genetic risk can not define a precise heritability. The epigenetic factors may explain the mechanisms which are able to drive cells with the same genotype towards different phenotypic identities, starting from the normal cells: this research trend represents one of the best promises in cancer research [21]. DNA methylation, histone modifications, and the chromatin structure are profoundly altered in human cancers, promoter DNA methylation being the most widely studied epigenetic modification of human cancers [22]. Kulis and Esteller (2010) considered that DNA methylation is a "soft" and potentially reversible change to the genome that can define or adapt to tumor biology and is functionally equivalent to genetic changes like mutations or deletions. Cancer cells display various functional genomic alterations, and epigenetic alterations play a key role in explaining them. Such DNA sequence-independent and heritable changes in cancer cells include DNA and histone covalent modifications: global DNA hypo-methylation, regional hypermethylation, and altered histone modifications. Genome-wide DNA 
hypomethylation and local, i.e., tumor suppressor genes promoter, hyper-methylation has been suggested to be an important step in carcinogenesis [23]. Global DNA hypomethylation has been associated with chromosomal and genomic instability early in tumorigenesis, and also with high potential of aberrant oncogenes activation. Local DNA hyper-methylation may silence certain housekeeping genes, with a tumour suppressor role, controlling vital cell processes like cell cycle arrest, DNA repair, apoptosis, and cell adhesion. Such geneticepigenetic factors interplay is considered actually as the basic transformation process which determines the genome expression reprogramming in particular genes set, which is characteristic for the cancerous cell phenotype.

Canine cancer molecular investigation started almost two decades ago, and recent advances in epigenetic analysis technology have been accelerated this research domain. In a recent investigation, Ferraresso and colleagues suggested an important role of DNA methylation in canine diffuse large B-cell lymphomas [24]. DNA processing methods are still improving since their initial reports in 1970 , in order to be able to prove that DNA methylation cancer biomarkers are suitable for early detection and also to have utility across a range of areas relevant to cancer detection and treatment [25].

Another important cancer marker is linked with biochemical aspects of the methylation processes in a cell, with the generic name of "one-carbon metabolism". It is based in part on DNA and histone methyltransferases role, but mainly on methyl donor availability, SAdenosyl-methionine (SAM). It is an amino acid derivative, whose methyl group can not be synthesized by mammals and hence have to be provided through diet and properly processed by intrinsic, genetically controlled enzymes. Moreover, SAM and its product, Sadenosylhomocysteine $(\mathrm{SAH})$, are controlled by strict cell biochemical and thermodynamic factors imposing particular enzyme-catalyzed reaction conditions in normal cells. These are expressed in the Michaelis-Menten coefficient and a conventional ratio of SAM to SAH values, named "methylation index". Particular deviations of this ratio, especially towards the lower levels, are considered today as relevant to genome instability and hence various diseases (cardiovascular, Alzheimer's, cancer) [26].

The same methylation index is linked not only with DNA methylation but also with histone methylation processes. Therefore, this work is pointing towards a recognized epigenetic marker. Histone H3 methylated in lysine (K) 9 (H3K9-trimethylated), which is indicative of particular genes suppression in the tumor genome. Staining through immunohistochemical methods, the chromatin in tumor tissues, and comparing the results with the staining of surrounding normal cells has been a frequent approach of the genome structure dynamics in tumor development research.

Few such studies are reported so far in dogs. However, comparison with human models has provided a link to the inflammation processes very recently. It was known that mammary tumors develop spontaneously in dogs with the clinically apparent intact immune system. A special interest is focused, therefore, on pre-invasive tumor tissue lesions, and their link with the inflammation and immune processes. Therefore, the canine model offers an excellent resource to explore prevention strategies for triple-negative breast cancer in females, particularly high-risk BRCA1/2 mutation carriers, especially because dogs with premalignant lesions may rapidly progress to invasive cancer, unfortunately in one year [27]. 


\section{Materials and Methods}

Tumour tissues have been collected from dogs during surgery in private offices and at the Faculty for Veterinary Medicine, and subsequently preserved under $-80^{\circ} \mathrm{C}$ until processed for DNA extraction and analysis. Parts of the same tumors were transported to the Faculty of Biology-Department of Cell Biology, University of Bucharest, and processed immediately after surgery for characterization of the normal and tumor parts of the bioptic tissues and for immunohistochemical estimations. Also, parts of the biopsies were transported to the National Institute for Biological Sciences, for particular processing in order that the methylation index to be estimated, and towards "Stefan Nicolau" National Institute of Virology, for the DNA methylation analysis.

A. H3K9 methylation detection was approached through Immunohistochemistry protocols: tissues samples were fixed in Bouin solution, dehydrated and embedded in paraffin; $5 \mu \mathrm{m}$-thick sections were sequentially incubated in $3 \% \mathrm{H} 2 \mathrm{O} 2$ to remove endogenous peroxidase (10 min.), washed in phosphate-buffered saline (PBS) and incubated with 2\% bovine serum albumin (BSA, fraction $\mathrm{V}$ ) to remove non-specific background staining (30 min.). Sections were incubated overnight, at $40^{\circ} \mathrm{C}$ with rabbit anti-H3K9 3 me antibody (Abcam), diluted 1:400, rinsed with PBS, and incubated with the secondary antibody, goat antirabbit IgG peroxidase conjugate (Rockland) diluted 1:1250, 1h, at room temperature. Each incubation step was followed by four $5 \mathrm{~min}$. rinses in PBS. To visualize the primary antibody binding sites (brown immunoreaction product), the sections were incubated for 10-15 min. in a solution of $0.05 \%$ 3,3'-diaminobenzidine tetrachloride (DAB) and $0.015 \%$ hydrogen peroxide, dissolved in PBS. The nuclei were counterstained with hematoxylin.

B. DNA methylation estimation was performed at the whole genome as well as in situ, at specific genes, BRCA1, and BRCA2 coding genes. The DNA analysis involved the following protocols:

1. DNA Extraction: in a $1.5 \mathrm{ml}$ Eppendorf safe-lock tube were added fragments of tumor tissue and fresh $100 \mu \mathrm{l}$ extraction buffer (Qiagen), and $10 \mu \mathrm{l} \mathrm{RN}$-ase A have been added. Sections were incubated for one hour at $37^{\circ} \mathrm{C}$, then $10 \mu \mathrm{l}$ of proteinase $\mathrm{K}$ (Qiagen) was added, and the samples were incubated overnight at $50^{\circ} \mathrm{C}(12-18 \mathrm{~h})$.

2. Whole DNA methylation level has been estimated by methylation sensible restriction of genomic DNA extracted from biopsic tissues based on the use of isoschizomer enzyme pairs, which are sensible-HpaII and insensible-MspI to internal methylated cytidine reissues of the same recognition site.

3. "In situ" DNA methylation estimation was approached through the MS-PCR test (methylation-specific PCR test, after [28]) on the promoters of BRCA1 and BRCA2 genes. It is represented by a modified PCR reaction that includes a preliminary step of the selective mutation of the DNA strands having the same nucleotide sequence but a different distribution of methylated cytidine residues. This step involves sodium bisulfite treatment so that the analyzed DNA to be accessible to DNA polymerase in mutated forms, which correspond to methylated/unmethylated initial forms of the same DNA sequences. The protocol of MS-PCR included the following steps:

Bisulfite treatment and selectively mutated DNA purification: $1.5 \mu \mathrm{g}$ of DNA was denatured in $5.5 \mu \mathrm{l}$ of $0.2 \mathrm{M} \mathrm{NaOH}$ for $10 \mathrm{~min}$ at $37^{\circ} \mathrm{C}$. Then, $30 \mu \mathrm{l}$ of freshly prepared $10 \mathrm{mM}$ hydroquinone (Sigma) and $520 \mu \mathrm{l}$ of $3 \mathrm{M}$ sodium bisulfite (Sigma) at pH 5.0 were added and mixed. The samples were overlaid with mineral oil to prevent evaporation and incubated at 
$50^{\circ} \mathrm{C}$ for $16 \mathrm{~h}$. The bisulfite-treated DNA was isolated using the Wizard DNA Clean-Up System (Promega). 900 $\mu$ l clean-up solution is added to the samples treated with bisulfite and taken from under the oil. The column was washed with $2 \mathrm{ml} 80 \%$ isopropanol, placed in another $1.5 \mathrm{ml}$ Eppendorf tubes and centrifuged for 2 minutes at 14,000rpm. The DNA was eluted by $50 \mu \mathrm{l}$ of warm water, and $5.5 \mu \mathrm{l}$ of $3 \mathrm{M} \mathrm{NaOH}$ were added for $5 \mathrm{~min}$. The DNA was cold ethanol (100\%) precipitated with $17 \mu 110 \mathrm{M}$ ammonium acetate as a carrier and resuspended in $20 \mu \mathrm{l}$ of water. Bisulfite-treated DNA was stored at $-20^{\circ} \mathrm{C}$ until ready for use. The tubes are centrifuged at $14,000 \mathrm{rpm}$ at $4^{\circ} \mathrm{C}$ for 25 minutes. The supernatant was discarded and washed with $250 \mu 170 \%$ ethanol, centrifuge at $14,000 \mathrm{rpm}$ for 5 minutes. The supernatant was mixed, dried at room temperature for 10 minutes, and separated on ice in 30-50 $\mu$ l bidistilled water and stored at $-80 \mathrm{oC}$. The principle of this bisulfite treatment of DNA is based on the selective chemical conversion of all non-methylated cytosines into uracil while the methylated cytosines remain unchanged. Thus after bisulfite treatment, the same DNA sequence will depend on the original DNA methylation pattern.

$M S-P C R$ : PCR primer sets specific for methylated (M) and respectively unmethylated (U) form of the initial DNA, which corresponds to different fragments from canine BRCA1 and 2 genes promoters, were chosen based on MethDb map [29] (indicative for the densest $\mathrm{CpG}$ clusters in the promoter of the studied genes). Bisulfite treated DNA was used for each MSPCR reaction for $B R C A 1$ and, respectively $B R C A 2$ promoter methylation estimation, using one pair of the same DNA for each tissue sample.

PCR reaction mixture $(20 \mu \mathrm{l}$ mix) contain: $2 \mu \mathrm{l} \mathrm{DNA}, 1.5 \mathrm{mM} \mathrm{MgCl} ; 200 \mu \mathrm{M}$ dNTPs; 100pmoli from each primer and 1U Platinium Taq (Invitrogen). PCR condition used Biometra Termocycler: primary denaturation at $94^{\circ} \mathrm{C} / 10 \mathrm{~min} ; 35$ cycles programs which included denaturation at $94^{\circ} \mathrm{C} / 30 \mathrm{sec}$.; elongation at $55^{\circ} \mathrm{C} / 30 \mathrm{sec}$., for $B R C A 1$; and at $57^{\circ} \mathrm{C} / 30 \mathrm{sec}$. for BRCA2; extension step included first treatment at $72^{\circ} \mathrm{C} / 30 \mathrm{sec}$., and finally at $72^{\circ} \mathrm{C} / 7 \mathrm{~min}$. Two methylated and unmethylated primer pairs were used for the same DNA sequence in pairs of the same sample. We selected PCR primers for BRCA $1-150 \mathrm{bp}$ for methylated samples and $151 \mathrm{bp}$ for unmethylated samples; for BRCA $2-155 \mathrm{bp}$ for methylated samples and $150 \mathrm{bp}$ for unmethylated samples.

The sequences of primers used for $B R C A 1$ and $B R C A 2$ gene promoters were as follows:

For BRCA1:

U left :3'- AATGGAAGAATTATTAGGGT

U right: 3'-AAAACCCAAAACAACAAAAA

M left:3'TGAATGGAAGAAATTATTAGG

M right: 3'-TCTCCATAAAAAAACTAAAA

For BRCA2:

U left: 3'-TTAGGAGTAATAGTTTAGTG

U right: 3'-CATAAAAAAAAACTAAAATA

M left:3'- AAACCCAAAACACAAAAAACG

M right: 3'-TTAGGAGTAATACTTTTACTG

MS-PCR Amplicons were analyzed through gel Electrophoresis in 0.8\% agarose and visualized in UV.

C. Methylation index evaluation. The determination of $S A M$ and $S A H$ was realized by HPLC. HPLC system estimation of SAM and SAH metabolites of the methyl donor SAM pathways has been performed by TCA extraction of these compounds. 
Chemical compounds: the SAM (Sigma) and SAH (Sigma). All the other reagents, methanol (Ridel-de Haen), acetonitrile (Sigma-Aldrich), $\mathrm{KH}_{2} \mathrm{PO}_{4}$ (Sigma), $\mathrm{K}_{2} \mathrm{HPO}_{4}$ (Sigma) heptanesulphonic acid (Sigma), hydrochloric acid (Merk), were analytical pure or of chromatographic grade and they were used after filtration. $\mathrm{H}_{2} \mathrm{O}$ was ultrapure, Millipore. The chromatographic measurements were performed using a complete Jasco HPLC system with a Nucleosil 100-10C18 $\mu \mathrm{m}$ 25x 0.46, Teknokroma column, and a FP-2020-Plus Intelligent Fluorescence Detector, set at appropriate excitation and emission wavelengths.

Samples preparation: a small amount of tissue (15-20 mg) was placed in an Eppendorf tube, $1.5 \mathrm{~mL}$. The protein was precipitated by adding $200 \mathrm{ml}$ trichloroacetic acid $40 \%$. To remove the precipitated protein, the tubes were centrifuged at $25,000 \mathrm{~g}$ for $10 \mathrm{~min}$ at $5^{\circ} \mathrm{C}$. The supernatant with SAM and SAH was then transferred to centrifugal filter units (Ultrafree-MC, $0.45 \mathrm{~mm}$; Millipore), an equal volume of diethyl ether was added (to extract lipids and excess trichloroacetic acid) and after the tubes were centrifuged to separate the phases. The top layer was drawn off and discarded.

HPLC analysis was performed by a method described previously [30]. Because SAM and SAH have not native fluorescence properties, in order to do them compatible to HPLC-FL analysis, the compounds found in tissue samples underwent pre-column derivatization. The derivatization reagent used was chloroacetaldehyde $45 \%$, which in the presence of sodium acetate formed the fluorescent SAM and SAH 1, $\mathrm{N}^{6}$-ethanol derivatives. After derivatization, $20 \mu \mathrm{L}$ of the sample was injected in the HPLC system. The fluorescent SAM and SAH $1, \mathrm{~N}^{6}-$ ethanol-derivatives were monitored at an excitation wavelength of $\lambda_{\text {ex }} 270$ and an emission wavelength of $\lambda_{\mathrm{em}} 1 / 4410 \mathrm{~nm}$. The experiments were performed at room temperature, with a flow rate by $1 \mathrm{~mL} / \mathrm{min}$ of mobile phase $\left(\mathrm{KH}_{2} \mathrm{PO}_{4}, 5 \times 10^{-2} \mathrm{~mol} / \mathrm{L}\right.$, and heptanesulfonic acid, $10^{-2}$ $\mathrm{mol} / \mathrm{L}$ containing methanol $30 \%$, adjusted to $\mathrm{pH} 4.30$ with phosphoric acid and isocratic elution), for 30 min per samples.

\section{Results and Discussion}

A group of 9 canine tissues extracted from cancer patients was investigated for the methylation epigenetic markers, including DNA methylation and histone methylation processes, associated with the methylation index of the tissues calculated based on the levels of methyl donor SAM and its product SAH. Control tissues were considered the normal surrounding cells to the tumor tissue. The canine mammary samples were sorted into two groups diagnosed based on anatomy-pathology criteria: the first four as benign, the last five being tested as malignancies.

\subsection{Epigenetic histone methylation markers.}

\subsubsection{Immunohistochemical analysis.}

Results obtained by IHC detection of histone $\mathrm{H} 3$ lysine $(\mathrm{K})$ tri-methylation (H3K9 trime) are represented in Fig. 1 and are suggesting the following aspects: staining of H3K9 trimethylated showed a perinuclear and even cytoplasmic localization. Significant histopathologic changes such as alveoli, prominent numerous large vacuoles and nucleoli, and lumenal margins accentuated are indicating typical alveolar hyperplasia. These results are in accordance with literature reporting particular epigenetic factors detected in malignant tissues such as the vast localization of the silenced chromatin at the peripheral of the tumor nucleus, 
represented by the accumulation of the antiH3K9 tri-methylated antibody marks. The morphological alterations are concomitant with loss of nuclear gene expression; instead, a prominent cytoplasmic or perinuclear localization, especially in tissue samples marked as malignant. Such chromatin H3K9 methylation pattern has been associated in the literature with particular chromatin dynamics in inflammation, immune processes activation through autophagy, indicative of cancer-associated cell proliferation, intensive apoptosis, or tumor progression stage through necrosis processes [31].

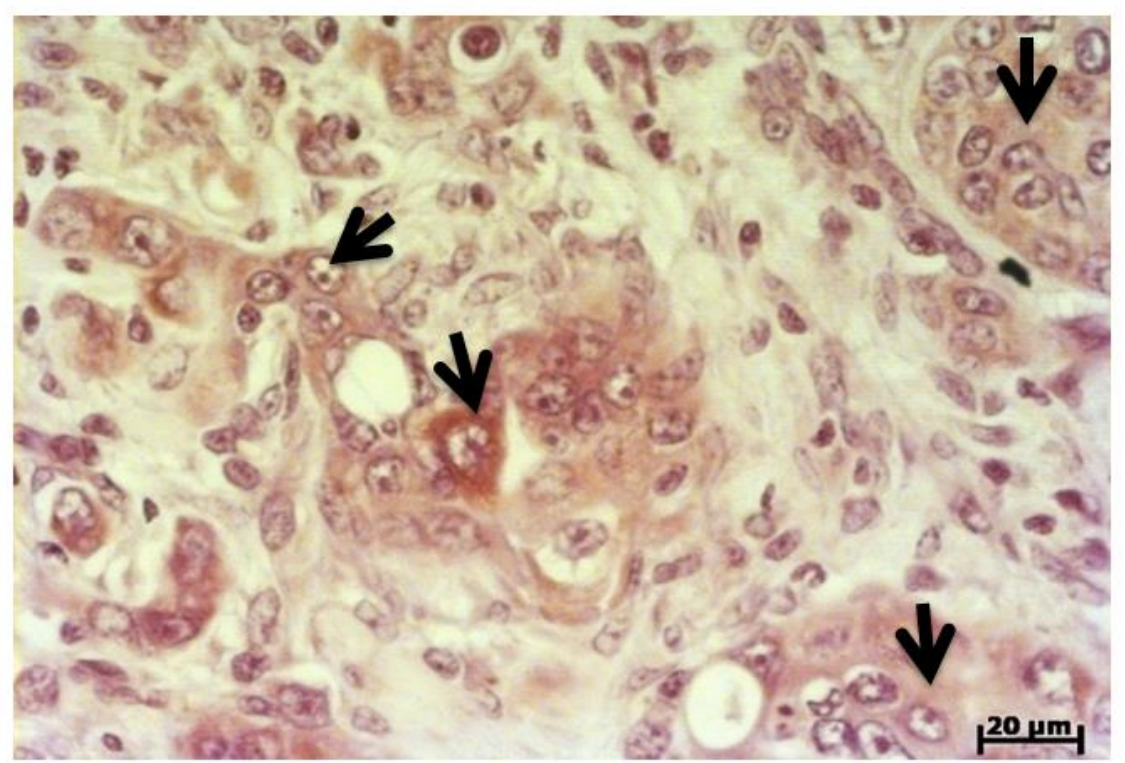

Figure 1. Staining histone H3K9 tri-methylated in the tumor tissue. Intense nuclear and cytoplasmic staining is observed in cells of a mixed malign/benign tumor from a dog. $\mu \mathrm{m} 20$. Perinuclear and cytoplasmic brown color distribution concomitant with the vacuole number increase.

3.2. Epigenetic markers associated with genome instability through global DNA hypomethylation and concomitant "in situ" (in particular genes) DNA methylation.

Global (genomic) and "in situ" (at particular gene promoters) DNA methylation level has been estimated in order to highlight the malignant characteristics of the tumor tissues.

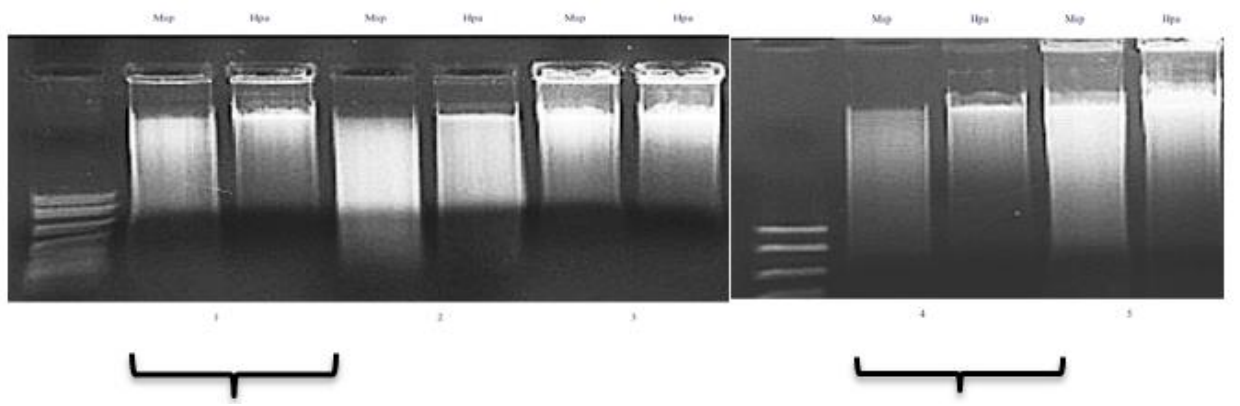

Figure 2. The methylation pattern of global (genomic) DNA. Restriction of extracted DNA from canine mammary tumor tissues was realized with pairs of isoschizomer enzymes (MspI/HpaII). Electrophoresis was performed in pairs of the same sample, one well for MSP! restriction and one for HpaII restriction. Genomic methylated DNA is marked for samples nr. 1, 4. which may be considered as being associated with the benign

state. The rest of the samples presented demethylated genomic DNA, associated with the malign state (according to the diagram represented in Fig.3).

The genome methylation test results indicated a sustained loss of global DNA methylation while tumor develops from the benign towards the neoplasic (malignant) stage: 
The analysis of the electrophoretic profiles of the DNA restriction with the MspI / HpaII isoschizomer enzyme pairs revealed a global (genome) hypomethylation of the DNA from the malignant breast tumor tissue compared to an increased DNA methylation pattern in the case of benign tumors (Fig.2 tags are used to mark the methylated state of DNA sample pair).

The methylated genomic state was observed especially in the group of benign tissues (1,4 of 1-4), whereas the malign group was mainly found as hypomethylated (sample 5). The explanatory diagrams of the restriction of genomic DNA with isoschizomer pairs of enzymes accompany the electrophoretic profiles in Fig.3.

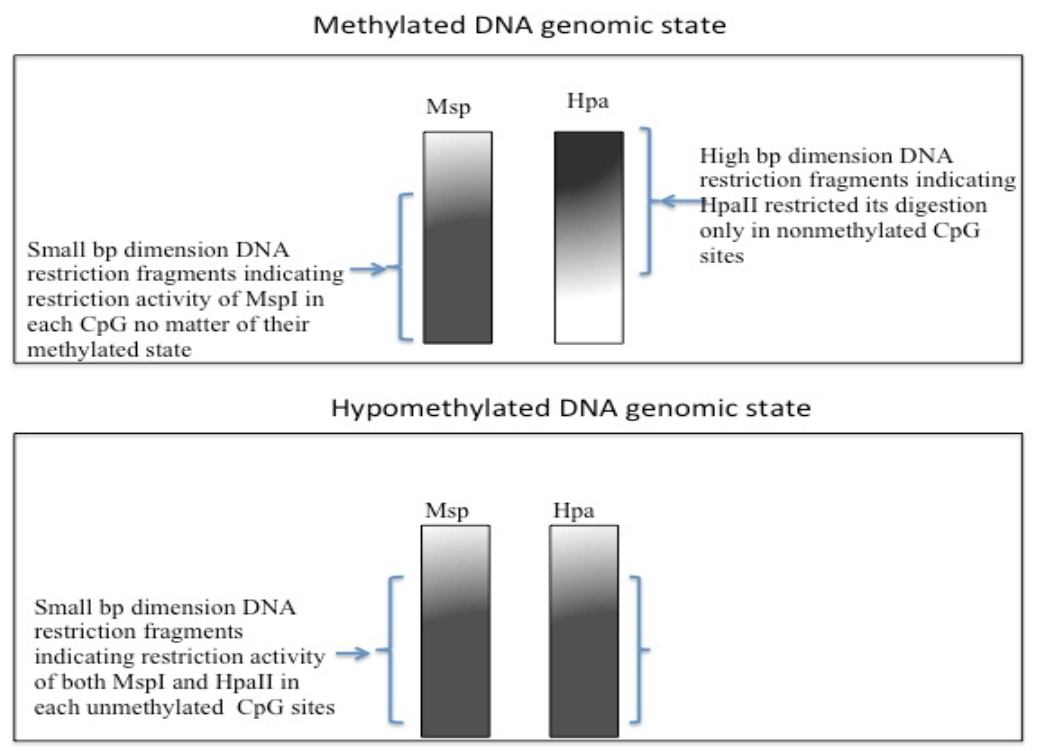

Figure 3. Diagram explaining the distribution of restriction fragments in MspI and, respectively, HpaII treated genomic DNA samples.

Similar results are reported in the literature for any type of tumors in humans and dogs and the genome instability is the generally accepted association with such DNA methylation pattern, especially in that dinucleotide $\mathrm{CpGs}$ that are not part of CpGIs (CpG islands, which are mainly localized in genes promoters) [32].

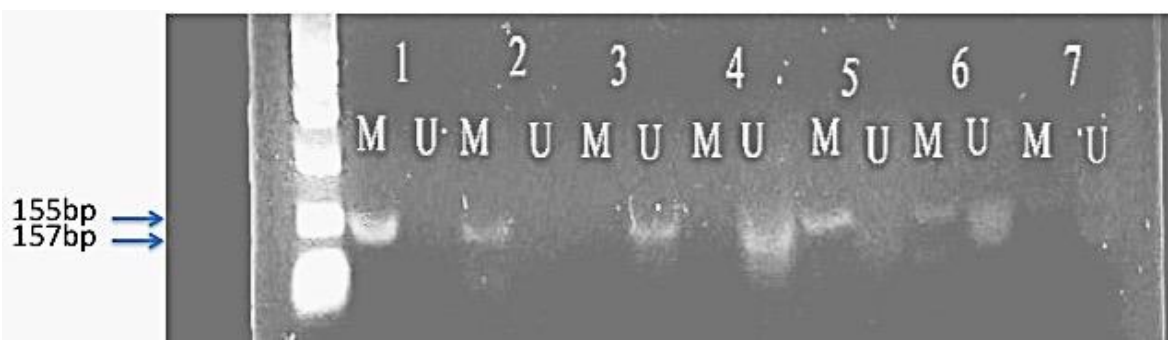

Figure 4. Fig. 3 "In situ" BRCA2 promoter methylation (amplicon 155pb-M; 157pb-U). Methylated DNA samples for BRCA2 gene promoter are 1,2,5,6. The unmethylated samples: 3,4,6, while the sample nr. 6 presented both methylated and unmethylated alleles.

Another aim of this study was to prove the involvement of the "in situ" DNA hypermethylation processes in the malignant transformation in dogs at the level of breast cancer risk genes $B R C A 1$ and $B R C A 2$. Our results suggest mixed aberrant methylation of BRCA1 and $B R C A 2$ gene promoters detected in tumor fragments in both benign, respectively, malign state (Fig. 4 and, respectively, Fig.5). The BRCA1 and BRCA 2 promoter hypermethylation have been proved by MS-PCR, which is in accordance with some of the literature reports suggesting the involvement of the epigenetic factors in the decreased gene expression of both genes in 
human and canine mammary tumors $[33,34]$. However, there are also numerous other reports pointing to mutation causes in the promoter genes for their variable gene expression in mammary tumors. According to studies envisaging the probability of developing human ovarian or breast cancer, germline mutations in BRCA1 or BRCA2 are known to lead to high risk.

These genes can also be involved in the development of sporadic tumors either through their mutated or methylated forms. In human medicine, both genes may carry hereditary mutations. However, in veterinary medicine, the hereditary aspect, as well as the dynamics of their expression is still under debate as indicated by recent literature; however, several breeds are thought to be predisposed to mammary cancer $[35,36]$.

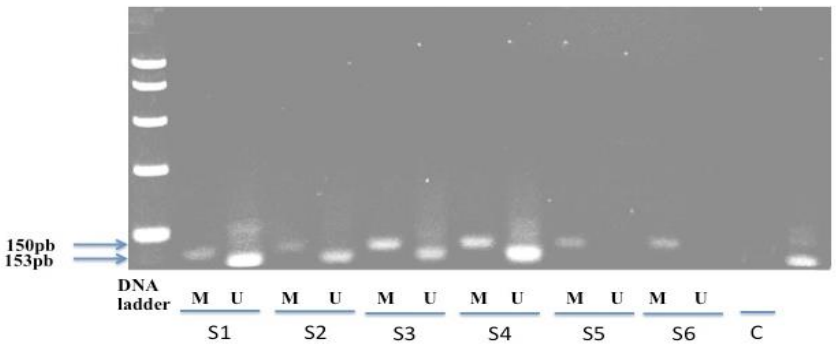

Figure 5. "In situ" BRCA1 promoter methylation (amplicon 150pb-M and 153pb-U). Samples nr. 1,2,3, 4 and 6 presented $B R C A 1$ gene promoter methylated.

In this study, we investigated the interrelationship between changes in DNA methylation and histone $\mathrm{H} 3 \mathrm{~K} 9$ methylation in canine mammary gland tumors in order to associate them with specific morphological features indicative of cancer progression. It is important to notice that malignant transformation may be triggered not only by methylation dynamics on DNA but also on the histones, such as $\mathrm{H} 3$ histone. Altered levels of methyltransferases that modify lysine 9 (K) of histone $\mathrm{H} 3$ (H3K9) by tri-methylation correlate with changes in molecular signaling and disruption of the cell cycle in cancer cells possibly by aberrantly silencing them. Moreover, gene repression processes are signaled in chromatin by particular nuclear compartmentation at the nuclear periphery. This study suggests crosstalk between DNA and histone methylation processes linked with subtle epigenetic signs, which may be pointing to cancer initiation and progression; such well known epigenetic marks in human cancers are also proven in canine models in many cancer types, including the mammary gland tumors [37].

\subsection{Methyl donor level and the methylation index estimation in tumor tissue.}

HPLC estimation of methyl donor SAM and its product from cellular trans-methylation reactions indicated a pronounced decrease of SAM versus SAH, typical for tumor tissues where global DNA hypomethylation occurs. The staging of tumorigenesis progression was established by following the SAM / SAH ratio designated as the methylation index of the tissue. The methyl donor SAM is continuously decreasing during cell methylation reactions as it results in SAH, the homocysteine precursor, and an important mutator agent. Therefore, SAM level must continuously be recovered from the external (diet) methyl donors, such as folates, choline, betaine [38]. Deficiencies in such nutritional factors during lifetime showed a strong association with any type of cancer. Literature reports are characterizing malignant state by high homocysteine and, more correctly by elevated SAH, and concomitantly decreased SAM levels $[39,40,41]$. This report showed a relative decreased value of the methylation index 
(SAM to SAH ratio) for malignant tumors (5-9) as compared with the benign ones(1-4). A better correlation with malignancy might is considering the observation of an increasing tendency in SAH concentration. At the same time, SAM was found in a relatively steady state in both tumor types (Table 1).

Table 1. Variation of the tissue methyl donor SAM and its product SAH levels. The methylation index varied according to the benign (1-4) and malign (5-9) state.

\begin{tabular}{l|l|l|l} 
Sample nr. & SAM $(\mathrm{mol} / \mathrm{L})$ & SAH $(\mathrm{mol} / \mathrm{L})$ & Ratio SAM/SAH \\
\hline 1 & 8.24 E-07 & 2.78 E-08 & 19.65 \\
\hline 2 & $7.91 \mathrm{E}-07$ & $2.05 \mathrm{E}-08$ & 38.56 \\
\hline 3 & $7.31 \mathrm{E}-07$ & $3.98 \mathrm{E}-08$ & 18.35 \\
\hline 4 & $9.72 \mathrm{E}-07$ & $2.82 \mathrm{E}-08$ & 34.46 \\
\hline 5 & $7.43 \mathrm{E}-07$ & $6.52 \mathrm{E}-08$ & 11.39 \\
\hline 6 & $8,85 \mathrm{E}-07$ & $7,62 \mathrm{E}-08$ & 11,61 \\
\hline 7 & $8.57 \mathrm{E}-07$ & $8.80 \mathrm{E}-08$ & 9.74 \\
\hline 8 & $7.89 \mathrm{E}-07$ & $4.78 \mathrm{E}-08$ & 16.48 \\
\hline 9 & $9.88 \mathrm{E}-07$ & $6.15 \mathrm{E}-08$ & 16.07
\end{tabular}

A consensus regarding the epigenome in cancer is presently considering a crosstalk between three gene expression regulation processes, including transcriptional (at chromatin level as DNA methylation and histone covalent modifications), posttranscriptional (as expression processes of non-coding DNA in cytoplasm microRNA transcripts) and cytoplasm posttranslational protein modifications ones. Any alteration in these gene function controlling processes such as aberrant hyper- or hypo-methylation as well as over- or low- the expression of microRNA species is considered presently potential markers of early cancer initiation events or tumor development stages. Our results on chromatin remodeling caused by either DNA hypomethylation or hypermethylation process accompanied by the increase in histones $\mathrm{H} 3 \mathrm{~K} 9$ trimethylated and its extension from the peripheral nuclear membrane in the cytoplasm have been recently described as transcriptional epigenotype patterns marking particular inflammation processes initiating cancer transformation and further tumor progression $[42,43,44]$.

As for mammary gland tumors in humans and dogs, the critical BRCA1 and BRCA2 genes are still in focus for clarifying their tumor suppressor roles. Their variable expression in tumor development has been described as being caused either by mutations or methylation processes; hence the attempt to designate them as markers for heritability of mammary cancers in both humans and dogs is still waiting for detailed molecular mechanisms. [45,46, 47,48]. Our results suggest that both genes can have mixed methylation patterns in benign and malign tumors, suggesting a dynamic gene reprogramming during the canine tumor development through their promoter methylation. Such data should further be completed by involving more genes in order to be able to differentiate the stromal reprogramming in benign and malignant naturally occurring canine mammary tumors, as reported recently [49]. New findings highlighted the potential of deciphering the variable $B R C A 2$ gene expression mechanism for the identification of efficient drug targets in mammary cancer therapy [50].

As it was already mentioned, dogs will be increasingly used model for cancer investigation, especially as compared with human breast cancer, in order to develop new therapeutic or preventive schemes. These considerations come mainly from the sharing of the same environment with our pets and because the canine immune system and responses, in general, are very similar to those in humans. For example, even in cases of low-frequency cancers in dogs such as canine gliomas, comparative studies are performed. Recently, canine 
gliomas showed high similarity with human pediatric gliomas based on robust aneuploidy, mutational rates, the relative timing of mutations and DNA-methylation patterns [51]. Recent reports regarding more functional genome factors in canine cancers pointed towards mammary cancer immunotherapy solutions [52]. Although in dogs and human mammary cancer, similar markers have been detected, such as the steroid receptor, epidermal growth factor, and proliferation markers and, moreover, their treatment involved a common estrogen receptor inhibition process, so far there are few identical effects in using the same oncodrugs. An example is referred to as the study of the interaction of azete-phenylene-dibenzoic acid derivatives with BRCA-1 protein, which could be referred only to human breast cancer [53]. On the other hand, recently appeared that 4-thiazolidinone derivatives might currently be subject to extensive research both in veterinary and human medicine [54] [55].

\section{Conclusions}

We have approached particular epigenetic methods to investigate mammary cancer in dog tissues. The results have shown a correlation between the appearance of changes in three main components of the epigenetic information: global DNA hypomethylation, local DNA hypermethylation, and histone methylation. Also, the global DNA hypomethylation was shown to be accompanied by decreased SAM/SAH ratio, indicated by the increase in SAH concentration, as the tumor develops from the benign to malign state. The expression of critical genes for breast cancer: $B R C A 1$ and $B R C A 2$ were suggested to be prone to silencing through methylation processes as a measure of slight tumor progression towards malignancy. IHC analysis of the cell H3K9 tri-methylation pattern suggested the concomitant in situ methylation and repression of chromatin regions in nuclei concomitantly with evasion of chromatin in the peripheral nucleus membrane and cytoplasm, a process associated with inflammation and cancer initiation.

Although both in human breast cancer and canine mammary tumors, the critical genes with tumor suppressor role, $B R C A 1$, and $B R C A 2$ have been intensively studied for a long time, little is known yet about their mutated or epigenetic modification state and about their expression dynamics. Further studies of their role in carcinogenesis and their relation with other epigenetic and genetic factors should be carried out. As premalignant mammary lesions in dogs and humans display many of the same characteristics, and as these lesions are frequently spontaneous in dogs, which are sharing the same environment with humans, many researchers consider that dogs are an ideal model to study the breast cancerogenesis stages.

\section{Funding}

Research funded by Consiliul National al Cercetarii Stiintifice | Unitatea Executiva pentru Finantarea Invatamantului Superior, a Cercetarii, Dezvoltarii si Inovarii (Program PNCDI CEEX-VIASAN Modul I P-CD ACRONIM: REN, Ctr. Nr.117/2006-2008; COD MEC CEEXM1C2-2981, Director NC).

\section{Acknowledgments}

This research acknowledges the effort of the whole consortium in planning the experimental design and interpreting the results as well as disseminating them as posters at international scientific conferences on epigenetics and biochemistry. Each author has equally contributed to obtaining the project results. 


\section{Conflicts of Interest}

The authors declare no conflict of interest.

\section{References}

1. Shimizu, R.; Muto, T.; Aoyama, K.; Choi, K.; Takeuchi, M.; Koide, S.; Hasegawa, N.; Isshiki, Y.; Togasaki, E.; Kawajiri-Manako, C.; Nagao, Y.; Tsukamoto, S.; Sakai, S.; Takeda, Y.; Mimura, N.; Ohwada, C.; Sakaida, E.; Iseki, T.; Starczynowski, D.T.; Iwama, A.; Yokote, K.; Nakaseko, C. Possible role of intragenic DNA hypermethylation in gene silencing of the tumor suppressor gene NR4A3 in acute myeloid leukemia. Leuk Res. 2016, 50, 85-94, https://doi.org/10.1016/j.leukres.2016.09.018.

2. Lee, K.H.; Park, H.M.; Son, K.H.; Shin, T.J.; Cho, J.Y. Transcriptome Signatures of Canine Mammary Gland Tumors and Its Comparison to Human Breast Cancers. Cancers (Basel) 2018, 10, https://doi.org/10.3390/cancers10090317.

3. Baba, A.I.; Cătoi, C. Comparative Oncology. The Publishing House of the Romanian Academy, Bucuresti, 2007; pp. 34-46.

4. Gal, A.F.; Andriopoulou, Anna; Miclăuș, V.; Tăbăran, F.; Taulescu, M.; Nagy, A.; Rus, V.; Cora, Roxana; Vidrighinescu, Raluca; Cătoi, C. Comparative Data Concerning the Incidence of Tumors in Dogs in a Period of Ten Years in Athens (Greece) and Cluj-Napoca (Romania). Bulletin UASVM Veterinary Medicine 2015, 72, 371-277, http://dx.doi.org/10.15835/buasvmen-vm:11538.

5. Vilhena, H.; Figueira, A. C.; Schmitt, F.; Canadas, A.; Chaves, R.; Gama, A.; Dias-Pereira, P. Canine and Feline Spontaneous Mammary Tumours as Models of Human Breast Cancer. In: Pets as Sentinels, Forecasters and Promoters of Human Health. Pastorinho, M.; Sousa, A. Eds. Springer, Cham, Switzerland 2019; pp.173-207, https://doi.org/10.1007/978-3-030-30734-9.

6. Holen, I.; Speirs, V.; Morrissey, B.; Blyth, K. In vivo models in breast cancer research: progress, challenges and future directions. Dis Model Mech 2017, 10, 359-371, https://doi.org/10.1242/dmm.028274.

7. Balmain, A.; Harris, C.C. Carcinogenesis in mouse and human cells: Parallels and paradoxes. Carcinogenesis 2000, 21, 371-377, https://doi.org/10.1093/carcin/21.3.371.

8. Cabuy, E; Newton, C.; Roberts, T.; Newbold, R.; Slijepcevic, P. Identification of subpopulations of cells with differing telomere lengths in mouse and human cell lines by flow FISH. Cytometry 2004, 62, 150-161, https://doi.org/10.1002/cyto.a.20096.

9. Ghoncheh, M.; Pournamdar, Z.; Salehiniya, H. Incidence and mortality and epidemiology of breast cancer in the world. Asian Pac J Cancer Prev 2016, 17, 43-46, https://doi.org/10.7314/APJCP.2016.17.S3.43.

10. Sorenmo, K.U.; Rasotto, R.; Zappulli, V. Development, anatomy, histology, lymphatic drainage, clinical features, and cell differentiation markers of canine mammary gland neoplasms. Vet Pathol 2011, 48, 85-97, https://doi.org/10.1177\%2F0300985810389480.

11. Xavier P.L.P.; Cordeiro, Y.G.; Alexandre, P. A.; Pires, P.R. L.; Saranholi, B. H.; Silva, E. R.; Müller, S.; Fukumasu, H. An epigenetic screening determines BET proteins as targets to suppress self-renewal and tumorigenicity in canine mammary cancer cells. Scientific Reports 2019, 9, https://doi.org/10.1038/s41598019-53915-7.

12. Kaszak, I.; Ruszczak, A.; Kanafa, S.; Kacprzak, K.; Król, M.; Jurka, P. Current biomarkers of canine mammary tumors. Acta Vet Scand 2018, 60, https://doi.org/10.1186/s13028-018-0417-1.

13. de Almeida, M. M. M. F.; Nagashima, J. B.; Venzac, B.; Le Gac, S.; Songsasen, N. A dog oviduct-on-a-chip model of serous tubal intraepithelial carcinoma. Scientific Reports 2020, 10, https://doi.org/10.1038/s41598020-58507-4.

14. Goebel, K.; Merner, N.D. A monograph proposing the use of canine mammary tumours as a model for the study of hereditary breast cancer susceptibility genes in humans. Vet. Med 2017, 3, 51-62, https://doi.org/10.1002/vms3.61.

15. Hsu, N.C.; Huang, Y.F.; Yokoyama, K.K.; Chu, P.Y.; Chen, F.M.; Hou, M.F. Methylation of BRCA1 promoter region is associated with unfavorable prognosis in women with early-stage breast cancer. PLoS One 2013, 8, https://doi.org/10.1371/journal.pone.0056256.

16. Maués, T.; El-Jaick, K.B.; Costa, F.B.; Araujo, G.E.F.; Soares M V.G.; Moreira A.S.; Ferreira M.L.G.; Ferreira, A.M.R. Common germline haplotypes and genotypes identified in BRCA2 exon 11 of dogs with mammary tumours and histopathological analyses, Veterinary and Comparative Oncology 2018, 16, 379384, https://doi.org/10.1111/vco.12389.

17. Brandão, Y.O.; Toledo, M.B.; Chequin, A.; Cristo, T.G.; Sousa, R.S.; Ramos, E.A.S.; Klassen, G. DNA Methylation Status of the Estrogen Receptor $\alpha$ Gene in Canine Mammary Tumors. Vet Pathol 2018, 55, 510516, https://doi.org/10.1177/0300985818763711.

18. Martínez-Galán, J.; Torres-Torres, B.; Núñez, M.I.; López-Peñalver, J.; Del Moral, R.; Ruiz De Almodóvar, J.M.; Menjón, S.; Concha, A.; Chamorro, C.; Ríos, S.; Delgado, J.R. ESR1 gene promoter region methylation in free circulating DNA and its correlation with estrogen receptor protein expression in tumor tissue in breast cancer patients. BMC Cancer 2014, 14, https://doi.org/10.1186/1471-2407-14-59. 
19. Kim, N.H.; Lim, K.Y.; Im, K.S. Evaluation of clinicopathological characteristics and oestrogen receptor gene expression in oestrogen receptor-negative, progesterone receptor- positive canine mammary carcinomas. J Comp Pathol 2014, 151, 42-50, https://doi.org/10.1016/j.jcpa.2014.04.001.

20. Visan, S.; Balacescu, O.; Berindan-Neagoe, I.; Catoi, C. In vitro comparative models for canine and human breast cancers. Clujul Med 2016, 89, 38-49, https://doi.org/10.15386/cjmed-519.

21. Toh, T.B.; Lim, J.J.; Chow, E.K. Epigenetics in cancer stem cells. Mol Cancer 2017, 16, https://doi.org/10.1186/s12943-017-0596-9.

22. Jones, P.A.; Baylin, S.B. The epigenomics of cancer. Cell 2007, 128, 683-692, https://doi.org/10.1016/j.cell.2007.01.029.

23. Harman, R.M.; Curtis, T.M.; Argyle, D.J.; Coonrod, S.A.; Walle, G.R. A Comparative Study on the In Vitro Effects of the DNA Methyltransferase Inhibitor 5-Azacytidine (5-AzaC) in Breast/Mammary Cancer of Different Mammalian Species. Journal of Mammary Gland Biology and Neoplasia 2016, 21, 51-66, http://dx.doi.org/10.1007/s10911-016-9353-8.

24. Epiphanio, T.M.F.; de Azevedo Fernandes, N.C.C.; de Oliveira, T.F.; Lopes, P.A.; Réssio, R.A.; Gonçalves, S.; Scattone, N.V.; Tedardi, M.V.; Kulikowski, L.D.; Damasceno, J.; de Melo Loureiro, A. P.; Dagli, M. L. Z. Global DNA methylation of peripheral blood leukocytes from dogs bearing multicentric non-Hodgkin lymphomas and healthy dogs: A comparative study. PLoS ONE 2019, 14, https://doi.org/10.1371/journal.pone.0211898.

25. Locke, W.J.; Guanzon, D.M.C.; Liew, Y.J., Duesing, K.R.; Fung, K.Y.C.; Ross, J.P. DNA Methylation Cancer Biomarkers: Translation to the Clinic. Front. Genet 2019, 10, https://doi.org/10.3389/fgene.2019.01150.

26. Akhtar, M. K.; Vijay, D.; Umbreen, S.; McLean, C.J.; Cai, Y.; Campopiano, D.J.; Loake, G. J. Hydrogen Peroxide-Based Fluorometric Assay for Real-Time Monitoring of SAM-Dependent Methyltransferases. Frontiers in bioengineering and biotechnology 2018, 6, https://doi.org/10.3389/fbioe.2018.00146.

27. Abdelmegeed, S. M.; Mohammed, S. Canine mammary tumors as a model for human disease (Review). Oncology Letters 2018, 15, 8195-8205, https://doi.org/10.3892/ol.2018.8411.

28. Herman, J.G.; Graff, J.R.; Myöhänen, S.; Nelkin, B.D.; Baylin, S.B. Methylation-specific PCR: a novel PCR assay for methylation status of $\mathrm{CpG}$ islands. Proceedings of the National Academy of Sciences of the United States of America 1996, 93, 9821-9826, https://doi.org/10.1073/pnas.93.18.9821.

29. Li, L.C.; Dahiya, R. MethPrimer: designing primers for methylation. PCRs. Bioinformatics 2002, 18, 14271431, https://doi.org/10.1093/bioinformatics/18.11.1427.

30. Birsan, C.; Litescu, S.C.; Cucu, N.; Radu, G.L. Determination of Sadenosylmethionine and Sadenosylhomocysteine from human blood samples by HPLC-FL. Analytical Letters 2008, 41, 1720-1731, https://doi.org/10.1080/00032710802162236.

31. Dou, Z.; Ghosh, K.; Vizioli, M.G.; Zhu, J.; Sen, P.; Wangensteen, K.J.; Simithy, J.; Lan, Y.; Lin, Y.; Zhou, Z.; Capell, B.C.; Xu, C.; Xu, M.; Kieckhaefer, J.E.; Jiang, T.; Shoshkes-Carmel, M., Tanim, K.; Barber, G.N.; Seykora, J.T.; Millar, S.E.; Berger, S.L. Cytoplasmic chromatin triggers inflammation in senescence and cancer. Nature 2017, 550, 402-406, https://doi.org/10.1038/nature24050.

32. Ohta, H., Yamazaki, J., Jelinek, J., Ishizaki, T., Kagawa, Y., Yokoyama, N.,Nagata, N; Sasaki, N.; Takiguchi, M. Genome-wide DNA methylation analysis in canine gastrointestinal lymphoma. Journal of Veterinary Medical Science 2020, 82, 632-638, https://doi.org/10.1292/jvms.19-0547

33. Beetch, M.; Harandi-Zadeh, S.; Yang, T.; Boycott, C.; Chen, Y.; Stefanska, B.; Mohammed, S.I.. DNA methylation landscape of triple-negative ductal carcinoma in situ (DCIS) progressing to the invasive stage in canine breast cancer. Sci Rep 2020, 10, https://doi.org/10.1038/s41598-020-59260-4.

34. Armaou, S.; Pertesi, M.; Fostira, F.; Thodi, G.; Athanasopoulos, P.S.; Kamakari, S.; Athanasiou, A.; Gogas, H.; Yannoukakos, D.; Fountzilas, G.; Konstantopoulou, I. Contribution of BRCA1 germline mutations to breast cancer in Greece: a hospital-based study of 987 unselected breast cancer cases. Br J Cancer 2009, 101, 32-37, https://doi.org/10.1038/sj.bjc.6605115,

35. Azzollini, J.; Pesenti, C.; Pizzamiglio, S.; Fontana, L.; Guarino, C., Peissel, B.; Plebani, M.; Tabano, S.; Sirchia, S.M.; Colapietro, P.; Villa, R.; Paolini, B.; Verderio, P., Miozzo, M.; Manoukian, S. Constitutive BRCA1 Promoter Hypermethylation Can Be a Predisposing Event in Isolated Early-Onset Breast Cancer. Cancers 2019, 11, https://doi.org/10.3390/cancers11010058,

36. Rivera, P.; Melin, M.; Biagi, T.; Fall,T.; Häggström, J.; Lindblad-Toh, K.; von Euler, H. Mammary Tumor Development in Dogs Is Associated with BRCA1 and BRCA2. Cancer Res 2009, 69, 8770-8774, https://doi.org/10.1158/0008-5472.CAN-09-1725,

37. Cao, J.; Kouznetsova, V.L.; Tsigelny, I.F. Molecular Mechanisms of Canine Cancers. OBM Genetics 2019, 3 .

38. Newman, A.C.; Maddocks, O.D.K. One-carbon Metabolism in Cancer. Br J Cancer 2017, 116, 1499-1504, https://doi.org/10.1038/bjc.2017.118.

39. Alonso-Aperte, E.; González, M.; Póo-Prieto, R.; Varela-Moreiras, G. Folate status and $S$ adenosylmethionine/S-adenosylhomocysteine ratio in colorectal adenocarcinoma in humans. Eur J Clin. Nutr. 2008, 62, 295-298, https://doi.org/10.1038/sj.ejcn.1602722. 
40. Liu, C.C.; Ho, W.Y.; Leu, K.L.; Tsai, H.M.; Yang, T.H. Effects of $S$-adenosylhomocysteine and homocysteine on DNA damage and cell cytotoxicity in murine hepatic and microglia cell lines. J. Biochem. Mol. Toxicol. 2009, 23, 349-356, http://doi.org/10.1002/jbt.20298.

41. Xu, W.; Wang, F.; Yu, Z.; Xin, F. Epigenetics and Cellular Metabolism. Genetics \& epigenetics 2016, 8, 43-51, https://doi.org/10.4137/GEG.S32160.

42. Don, Z.; Ghosh, K.; Vizioli, G.; Zhu, J.; Sen, P.; Wangensteen, K.J.; Simithy, J.; Lan, L.; Lin, Y.; Zhuo, Z.; Capell, B.C.; Xu, C.; Xu, M.; Kieckhaefer, J.E.; Jiang, T.; Shoshkes-Carmel, M.; Ahasan Al Tanim, K.M.; Barber, G.N.; Seykora, J.T.; Millar, S.E.; Kaestner, K.H.; Garcia, B.A.; Adams, P.D.; Berger, S.L. Cytoplasmic chromatin triggers inflammation in senescence and cancer. Nature 2017, 550, 402-406, https://doi.org/10.1038/nature24050.

43. Holliday, H.; Baker, L.A.; Junankar, S.R.; Clark, S.J.; Swarbrick, A. Epigenomics of mammary gland development. Breast cancer research 2018, 20, https://doi.org/10.1186/s13058-018-1031-X.

44. Lutful Kabir, F.M.; Alvarez, C.E.; Bird, R.C. Canine mammary carcinomas: A comparative analysis of Altered gene expression. Vet. Sci. 2015, 3, https://doi.org/10.3390/vetsci3010001.

45. Sadia, H.; Manzoor, S.; Wajid, A.; Tayyab, M.; Firyal, S.; Hashmi, A.S.; Yaqub, T.; Mughal, Z.U.; Mehmood, A.K.; Awan, A.R.; Mahmood, K.; Khan, M.Y.; Wasim, M. Cox-2 and BRCA1 have altered expression profile in different canine tumors. Anim. Plant Sci. 2016, 26, 103-115.

46. Nieto, A.; Perez-Alenza, M.D.; Del Castillo, N.; Tabanera, E.; Castaño, M.; Peña, L. BRCA1 expression in canine mammary dysplasias and tumors: relations with prognostic variables. J.Comp.Pathol. 2003, 128, 260268, https://doi.org/10.1053/jcpa.2002.0631.

47. Yoshikawa, Y.; Morimatsu, M.; Ochiai, K.; Ishiguro-Oonuma, T.; Wada, S.; Orino, K.; Watanabe, K. Reduced canine BRCA2 expression levels in mammary gland tumors. BMC Vet Res 2015, 11, https://doi.org/10.1186/s12917-015-0483-9.

48. Cao, J.; Kouznetsova, V.L.; Tsigelny, I.F. Molecular Mechanisms of Canine Cancers. OBM Genetics 2019 , 3 .

49. Amini, P.; Nassiri, S.; Malbon, A.; Markkanen, E. Differential stromal reprogramming in benign and malignant naturally occurring canine mammary tumours identifies disease-modulating stromal components. Sci Rep 2020, 10, https://doi.org/10.1038/s41598-020-62354-8.

50. Thumser-Henner, P.; Nytko, K.J.; Rohrer Bley, C. Mutations of BRCA2 in canine mammary tumors and their targeting potential in clinical therapy. BMC veterinary research 2020, 16, https://doi.org/10.1186/s12917-020-2247-4.

51. Samirkumar, B.; Amin, K.J.; Anderson, C.; Boudreau, Elizabeth; Martinez-Ledesma, E.; Kocakavuk, E.; Johnson, K.C.; Barthel, P.F.; Varn, F.S.; Kassab, C.; Ling, X.; Kim, H.; Barter, M.; Lau, C.C.; Ngan, C.Y.; Chapman, M.; Koehler, J.W.; Long, J.P.; Miller, A.D.; Miller, C.R.; Porter, B.F.; Rissi, D.R.; Mazcko, C.; LeBlanc, A.K., Dickinson, P.J.; Packer, R.A.; Taylor, A.R.; Rossmeisl, J.H.; Woolard, K. D.; Heimberger, A.B.; Levine, J.M.; Verhaak, R.G.W. Comparative Molecular Life History of Spontaneous Canine and Human Gliomas. Cancer Cell 2020, 37, 243, https://doi.org/10.1016/j.ccell.2020.01.004.

52. Dow, S. A role for dogs in advancing cancer immunotherapy research. Research Front Immunol. 2020, 10, https://doi.org/10.3389/fimmu.2019.02935.

53. Figueroa-Valverde, L.; Francisco, D.C.; Rosas-Nexticapa, M.; Mateu-Armand, V.; Montano-Tapia, E.; HauHeredia, L.; Lopez-Ramos, M.; García-Cervera, E.; Gómez, P.E.; García-Martinez, R.; Estrella-Barrón, R.; Cauich-Carrillo, R.; Alfonso-Jimenez, A.; Cabrera-Tuz, J. Design and synthesis of two azete-phenylenedibenzoic acid derivatives and theoretical evaluation of their interaction with BRCA-1 protein. Biointerface Res. Appl. Chem. 2018, 8, 3412-3417.

54. Drapak, Iryna; Foliush, V.; Chaban, T.; Matiychuk, V. Synthesis antimicrobial and antitumor activities of 2[5-(2-R-benzyl)thiazol-2-ylimino]thiazolidin-4-ones. Biointerface Res.Appl.Chem. 2020, 10, 5507-5511, https://doi.org/10.33263/BRIAC103.507511.

55. Kobylinska, L.I.; Boiko, N.M.; Panchuk, R.R.; Grytsyna, I.I.; Klyuchivska, O.Y.; Biletska, L.P.; Lesyk, R.B., Zimenkovsky, B.S.; Stoika, R.S. Putative anticancer potential of novel 4-thiazolidinone derivatives: cytotoxicity toward rat C6 glioma in vitro and correlation of general toxicity with the balance of free radical oxidation in rats. Croatian medical journal 2016, 57, 151-163, https://doi.org/10.3325/cmj.2016.57.151. 